\title{
DIFFERENCES OF OXFORD EXERCISE VERSUS HOLTEN EXERCISE ON INCREASING THE QUADRICEPS FEMORIS MUSCLE STRENGTH
}

\author{
Muhammad Husien Syawaludin \\ Study Program of Physiotherapy, Health Polytechnics, Ministry of Health Surakarta/ \\ Masters Program in Public Health, Universitas Sebelas Maret
}

\begin{abstract}
Background: The quadriceps femoris is the most voluminous muscle of the human body. The muscular adaptation of the quadriceps muscle with advancing age changes its morphology and function. The musculature loses mass and volume (sarcopenia) decreases strength and coordination. Therefore, it is of utmost importance to improve lower limb muscle strength by exercise. The purpose of this study was to determine which exercise increases quadriceps femoris muscle strength between Oxford and Holten methods.

Subjects and Method: A randomized controlled trial was conducted at campus 2 Health Polytechnics Ministry of Health Surakarta, from February to March 2013. A sample of 62 women was divided into 2 groups (1) Oxford therapy and (2) Holten therapy. The dependent variable was quadriceps femoris muscle strength. The independent variables were Oxford and Holten therapies. Quadriceps femoris muscle strength was measured by $1 \mathrm{RM}$ submaximal Holten diagram. Mean difference of quadriceps femoris muscle strength between groups was assessed by independent t-test. Results: After intervention, there was no difference of quadriceps femoris muscle strength of women in Oxford group (Mean=20.37; $\mathrm{SD}=1.74)$ and Holten group (Mean= 20.94; $\mathrm{SD}=1.62$ ), with $\mathrm{p}=0.194$.
\end{abstract}

Conclusion: There is no difference of Oxford method and Holten method in quadriceps femoris muscle strength of women.

Keywords: Oxford exercise, Holten exercise, quadriceps femoris muscle strength

\section{Correspondence:}

Muhammad Husein Syawaludin. Study Program of Physiotherapy, Health Polytechnics, Ministry of Health Surakarta. Jl. Kapt. Adi Sumarmo, Colomadu, Karanganyar 57173, Central Java. Email: fahusein26@gmail. Mobile: 085728989309. 